\title{
Estimation of Serum Copper Levels in Oral Submucous Fibrosis Patients: A Quantitative Study
}

\section{Bhavna Tyagi ${ }^{1 *}$, Deepak Bhargava ${ }^{1}$, Ritika Sharma ${ }^{1}$, Vidyadevi Chandarvarkar $^{1}$ and Pradeep Sundersan ${ }^{3}$}

${ }^{1}$ Oral and Maxillofacial Pathology and Microbiology, Sharda University, India

${ }^{2}$ Ph.D (Education), American University, London, UK

*Corresponding Author: Bhavna Tyagi, Oral Pathologist, Oral and Maxillofacial

Pathology and Microbiology, Sharda University, Greater Noida, Uttar Pradesh, India.
Received: December 14, 2020

Published: January 23, 2021

(C) All rights are reserved by Bhavna Tyagi., et al.

\begin{abstract}
Context: Oral submucous fibrosis (OSMF) is documented as a potentially malignant disorder with a 7.6\% malignant transformation rate. Various trace elements such as, copper, zinc, and iron are getting much attention in the early recognition of cancer and potentially malignant disorders including OSMF.

Aim: To evaluate the levels of copper in the OSMF patients' blood serum and compare with healthy individuals.

Settings and Design: Quantitative research was conducted in the Department of Oral and Maxillofacial Pathology, Sharda University, Greater Noida. A total of 80 participants, out of which 20 participants were case-control (Batch I), and 60 diagnosed OSMF patients (cases) (Batch II, III and IV) participated.
\end{abstract}

Methods and Material: For estimation of serum copper, under sterile conditions, $3 \mathrm{ml}$ of the venous blood sample was collected. Serum was collected and evaluated by adding an instructed proportion of buffer, and the color reagents in the clean glassware.

Statistical Analysis: All the data was systematically tabulated and analyzed using SPSS statistical software by employing "One way ANOVA".

Results: The mean serum copper $(\mu \mathrm{g} / \mathrm{dl})$ level differed significantly $(\mathrm{p}<0.004)$ between all the batches. Mean serum copper $(\mu \mathrm{g} /$ dl) levels in Batch I, Batch II, Batch III, Batch IV was 103.43 \pm 5.88603, 105.1 \pm 5.99034, 121.55 \pm 8.08817, $134.825 \pm 18.23334$, respectively.

Conclusion: Serum copper levels can be used as a potential diagnostic and prognostic marker in the patient with OSMF condition.

Keywords: Oral Submucous Fibrosis; Trace Elements; Copper; Pre-Cancer; Diagnostic Marker; Serum Copper

\section{Abbreviations}

OSMF: Oral Submucous Fibrosis; LO: Lysyl Oxidase.

\section{Introduction}

Background

Oral submucous fibrosis (OSMF) is documented as a potentially malignant disorder with a 7.6\% malignant transformation rate. This disease is associated with betel chewing habits, therefore shows confinement to Southeast and South Asian countries, specifically India, with an approximately $6.42 \%$ prevalence rate. Further, this disease is more common in males than females, associated with a high prevalence rate of oral chewing habit in males. The age range of persons suffering from OSMF extends from 20 to 40 years [1]. By considering the transformation rate of this disease, 
it is paramount to follow effective early detection methodology. Recently various trace elements, for instance, Zinc, copper and iron, are getting much attention in the early recognition of cancer and potentially malignant disorders which includes OSMF [2,3].

Copper is considered the third most copious trace mineral in the human body. It functions as cofactor; furthermore, it is required for catalytic and structural properties of various vital enzymes, such as Cu-zinc super oxidase, lysyl oxidase, and dopamine beta-hydroxylase, and cytochrome c oxidase. Additionally, free copper ions contribute to reactive oxygen species formation. It is believed that copper plays a paramount role in OSMF pathogenesis, as copper and alkaloids content are high in the arecanut. Further, in commercial products for instance, Rajnigantha and pan masala, the copper content is higher than the raw areca nut. Following the study conducted by Trivedy., et al. (1999), the commercial products consist of $18 \pm 8.7 \mathrm{mg} \mathrm{kg}-1$ copper that is comparatively way more than the raw areca nut [4]. While consuming such commercial products and raw areca nut, a substantial copper amount is released into the saliva and absorbed in the oral mucosa, causing up-regulation of the Lysyl Oxidase (LO) in the oral mucosa, leading to fibrosis. However, LO up-regulation's detailed mechanism is not understood due to the short half-life of LO [5].

\section{Gap in Literature and Aim}

Various pieces of literature have attempted to evaluate the serum levels of copper in pre-malignant conditions and oral cancer, though the results are inconclusive (Tadakamadla., et al.) [18]. Furthermore, very few studies have been done to evaluate the copper levels in serum, particularly in OSMF patients. Therefore, by considering the role of copper in OSMF's etiopathogenesis and progression, this research was made to evaluate the levels of copper in the blood serum of patients with OSMF and compared with the expected levels of copper in healthy individuals. Early detection can be a useful tool to prevent the malignant transformation of this crippling disease.

\section{Materials and Method}

The research was conducted in the Department of Oral and Maxillofacial Pathology, Sharda University, Greater Noida. Prior conduction of this study, ethical clearance was obtained from the Institutional Ethical Committee. A total of 80 participants, 20 participants were case-control, and 60 diagnosed cases of OSMF (ac- cording to the classification given by Ranganathan K., et al. (2001)) [6] participated in this study.

The samples were categorized into four groups following the above-stated classification, as follows:

- Batch 1: Consisted of 20 cases of healthy control without any habit.

- Batch 2: Consisted of 20 cases of clinically diagnosed group I OSMF (Only symptoms, with no demonstrable restriction of mouth opening).

- Batch 3: Consisted of 20 cases of clinically diagnosed group II OSMF (Limited mouth opening $20 \mathrm{~mm}$ and above).

- Batch 4: Consisted of 20 cases of clinically diagnosed group III and IV OSMF (Mouth opening less than $20 \mathrm{~mm}$ and OSMF advanced with limited mouth opening along with pre-cancerous or cancerous changes seen throughout the mucosa). In contrast, pregnant women, patients with a history of treatment for OSMF, and taking supplements, including copper and Zinc, were excluded from this study.

For estimation of copper in the blood, under sterile conditions, $3 \mathrm{ml}$ of the venous blood sample was collected by venipuncture of the median cubital vein and kept upright at room temperature for approximately 30 minutes in red-capped vacutainer tube. Sample after 30 minutes was centrifuged at $3000 \mathrm{rpm}$ at four ${ }^{\circ} \mathrm{C}$ for five minutes. The serum collected from each was transferred to the storage vials and stored at $-20^{\circ} \mathrm{C}$ for one week till analysis. Serum samples were evaluated by adding an instructed proportion of buffer, and the colour reagents in the clean glassware. All the data was systematically tabulated and analyzed by SPSS statistical software by employing "One way ANOVA."

\section{Results and Discussion \\ Results}

All the test cases studied were adults above 18 years of the age with a range of 25 to 40 years. Mean age was $32.69 \pm 7.219$ (Table 1).

Out of 80 patients studied, 66 were males (82.50\%), and 14 were females (17.50\%).In Batch I, 10 participants were males (50\%), and 10 participants were females (50\%).In Batch II, out of 20 patients, all were males, i.e. $100 \%$. In Batch III, out of 20 patients, 18 were males (90\%), and 20 were females (10\%).In Batch 


\begin{tabular}{|l|c|c|c|}
\hline & N & Mean (Years) & Standard Deviation \\
\hline Batch I & 20 & 28.80 & 5.116 \\
\hline Batch II & 20 & 32.75 & 7.966 \\
\hline Batch III & 20 & 32.00 & 7.954 \\
\hline Batch IV & 20 & 37.20 & 5.095 \\
\hline TOTAL & 80 & 32.69 & 7.219 \\
\hline
\end{tabular}

Table 1: Age distribution of case-control and patients.

IV out of 20 patients, 16 were males (80\%), and 4 were females (20\%) elaborated in graph 1.

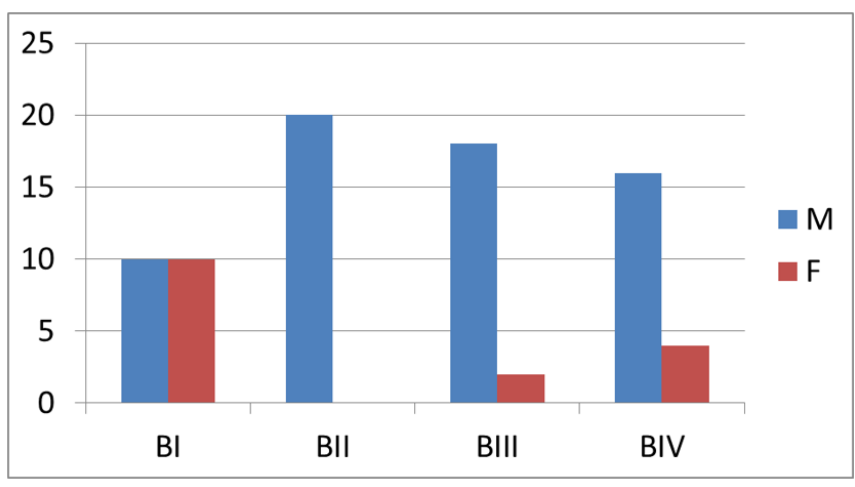

Graph 1: Sex distribution in all Batches.

It is evident from table 2 and graph 2 , the mean serum copper $(\mu \mathrm{g} / \mathrm{dl})$ level differed significantly $(\mathrm{p}<0.004)$ between all the batches. Mean serum copper $(\mu \mathrm{g} / \mathrm{dl})$ levels in Batch I, Batch II, Batch III, Batch IV was $103.43 \pm 5.88603,105.1 \pm 5.99034,121.55 \pm 8.08817$, $134.825 \pm 18.23334$, respectively. One way ANOVA revealed a statistically significant difference $(\mathrm{p}<0.005)$ in mean serum copper levels among patients in various clinical stages of OSMF with mean serum copper $120.4917 \pm 17.02976$ as elaborated in table 3 and graph 3.

\begin{tabular}{|l|c|c|c|c|}
\hline Batches & Number & $\begin{array}{c}\text { Mean } \\
(\boldsymbol{\mu g} / \mathbf{d} \mathbf{l})\end{array}$ & $\begin{array}{c}\text { Std. } \\
\text { Deviation }\end{array}$ & Significance \\
\hline B I & 20 & 103.43 & 5.88603 & \multirow{2}{*}{.004} \\
\cline { 1 - 3 } B II & 20 & 105.1 & 5.99034 & \multirow{2}{*}{} \\
\cline { 1 - 3 } B III & 20 & 121.55 & 8.08817 & \\
\cline { 1 - 3 } B IV & 20 & 134.825 & 18.23334 & \\
\hline
\end{tabular}

Table 2: Mean serum copper $(\mu \mathrm{g} / \mathrm{dl})$ in the study group and control group.

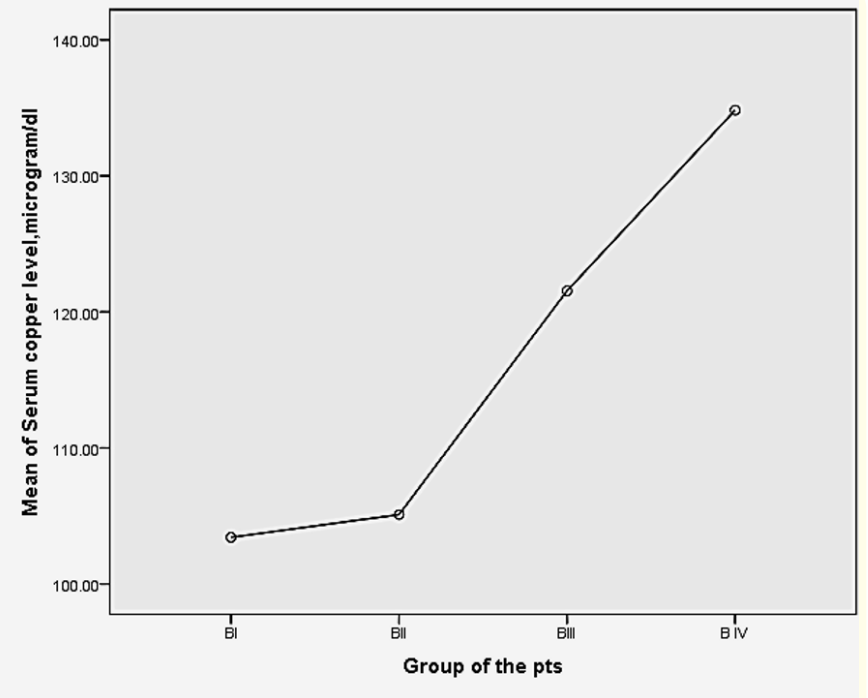

Graph 2: Mean serum copper $(\mu \mathrm{g} / \mathrm{dl})$ in the study group and control group.

\begin{tabular}{|c|c|c|c|c|}
\hline Batches & Number & $\begin{array}{c}\text { Mean } \\
(\mu \mathrm{g} / \mathrm{dl})\end{array}$ & Std. Deviation & Significance \\
\hline B II & 20 & 105.1 & 5.99034 & \multirow[t]{4}{*}{.005} \\
\hline B III & 20 & 121.55 & 8.08817 & \\
\hline B IV & 20 & 134.825 & 18.23334 & \\
\hline Total & 60 & 120.4917 & 17.02976 & \\
\hline
\end{tabular}

Table 3: Mean serum copper $(\mu \mathrm{g} / \mathrm{dl})$ values amongst the study group.

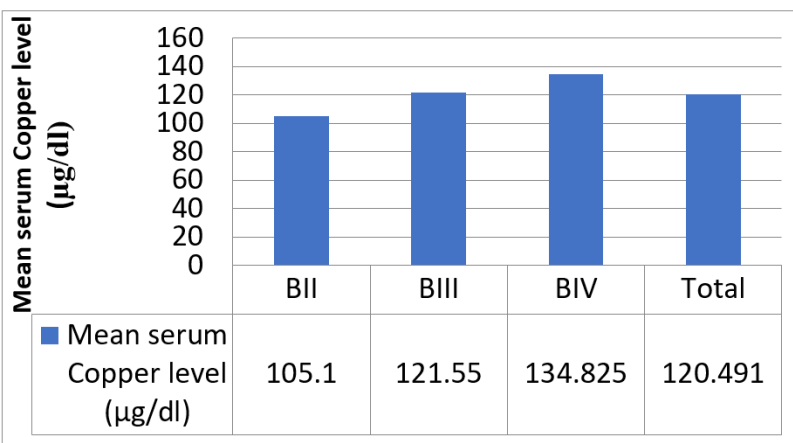

Graph 3: Serum copper level within all OSMF patients group. 
There was an increase in serum copper concentration as clinical stage increased, but the difference observed was not statistically significant $(\mathrm{p}<0.379$ ) between Batch I and II, the same is evident from Table 4. In contrast, there was a significant difference $(\mathrm{P}<$ 0.002) between the mean serum copper values of Batch I and III with mean copper values $103.43 \pm 5.88603$ and $121.55 \pm 8.08817$, respectively. Furthermore, one way ANOVA revealed a statistically significant difference in mean serum copper level among patients Batch IV and control group. There was a definite trend, as p-value was significant $(\mathrm{P}<0.001)$, elaborated in table 4 .

\begin{tabular}{|l|c|c|}
\hline $\begin{array}{c}\text { Batches } \\
\text { comparison }\end{array}$ & p-value & Significance \\
\hline BI and BII & 0.379 & Not significant \\
\hline BI and BIII & .002 & Significant \\
\hline BI and BIV & .001 & Significant \\
\hline
\end{tabular}

Table 4: Comparison of Mean serum copper ( $\mu \mathrm{g} / \mathrm{dl})$ in Batch I and II, Batch I and Batch III and Batch I and Batch IV.

\section{Discussion}

The cancer development is two-step process which commences as the initial precursor state (pre-cancerous/pre-malignant) followed by cancer development. Furthermore, the transformation rate of pre-malignant state and condition is high. Amongst premalignant state, OSMF has a particular concern as this condition predisposes the entire oral mucosa to acquire high malignant potential tendency $[7,8]$. Very few researches have been conducted to evaluate the role of trace elements in the diagnosis of the severity of the pre-malignant condition. Hence, this research has been conducted to estimate the level of serum copper at the different clinical staging of OSMF.

In the present research, 60 participants with OSMF and normal healthy 20 participants were included, with the age range of 25 to 40 years. Mean age was $32.69 \pm 7.219$. This age range is associated with changing lifestyle amongst youngsters linked with increased pan masala and tobacco chewing habits. The above-stated age results of this research are comparable to the researchers conducted by Yadav., et al. [9] Maher., et al. [10] and Hazarey., et al. [11]. Furthermore, out of 80 patients, 66 were males (82.50\%), and 14 were females $(17.50 \%)$, therefore showing high male predominance. A comparable male prevalence was reported by Kumar., et al. [12] and Srivastava., et al. [13].

OSMF is associated explicitly with areca nut consumption, and it is considered as the chief component of betel quid. The chew mix/ quid consists of a combination of slaked lime, tobacco, betel leaf and areca nut. Zaidi., et al. [13] had conducted a study to evaluate the presence of trace elements in various quid preparation through radiochemical neutron activation analysis. The author concluded that there are 36 trace elements in various concentrations in different quid preparations [14]. Furthermore, as per various literatures, copper is one of the components present in the chewing mix.

The serum copper levels in the present study were significantly higher $(\mathrm{p}<0.004)$, while comparing amongst all the batches. It was in correlation with the research by Shetty., et al. [15] and Balpande., et al. [16]. Furthermore, the serum copper levels when compared between the batches I and II showed no significant value. Moreover, the significant $p$-value $(p<0.002)$ was obtained when the comparison were made between batches I and III. Additionally, when serum copper levels were compared between two batches, batch I and batch IV had shown highly significant p-value, i.e. $\mathrm{p}<$ 0.001. Lastly, there was a definite trend as the serum copper level increased with severity of OSMF. The similar results were evident in the study conducted by Yadav., et al. [9] and Tadakamadla., et al. [18]. The research conducted by Vargheses., et al. [19] suggested significantly lower serum copper levels with increasing stage of OSMF, contrary to prior researches that could be because of difference in laboratory methodologies deployed and different patient selection criteria.

Moreover, Anuradha and Devi [20] found lower levels of plasma copper in OSMF patients. Though, the researchers included 22 participants in their study that was a smaller sample size as compared to most of the previous studies. Additionally, included patients had experienced appetite loss and inadequate diet intake that could affect the plasma copper levels. Other researches have documented high salivary copper [21] and high copper levels in the oral mucosal tissue [22,23]. Many other types of research, however, documented the significant higher serum level in OSMF patient $[16,17,24]$.

Therefore, the role of increased copper in carcinogenesis is being subjected to analysis. Increased intercellular copper levels can lead to the generation of hydroxyl radicals, which can cause the impaired structure of protein molecules and DNA. Additionally, copper lead to activation of various angiogenetic, a factor that plays 
a paramount role in metastasis and growth of tumour [25]. Furthermore, as per the research conducted by Jayadeep., et al. [26] ceruloplasmin (a copper transporting protein) is also increased during OSMF malignancy. However, ceruloplasmin serves as the copper ion source that can trigger LDL oxidation, associated with malignant transformation.

A limitation of this study is the comparatively small sample size as compared to many studies with the same aim. Further, dietary intake records were not described in this study; therefore, the diet influence on serum copper level is unknown. Lastly, only serum copper levels were examined, saliva and oral mucosal copper levels could be included for a better understanding of the role of copper in OSMF etiopathogenesis. Thus, future study should include salivary and oral mucosal tissue copper levels.

\section{Conclusion}

The number of OSMF patients is rising continuously; however, still, there is no proper understanding of the delineated etiopathogenetic mechanism linked to the formulation and progression of this crippling disease. It can be concluded for this present study that serum copper levels can be used as a potential diagnostic and prognostic marker in the patient with OSMF condition. Although, as there are various kinds of literature with a controversial report on the association between trace elements and OSMF, therefore further researches are anticipated with larger heterogeneous participants to support the hypothesis.

\section{Acknowledgement}

On behalf of my whole team, I would like to acknowledge the support for the biochemistry lab of Sharda University by Dr. G.R.K Rao (HOD), Mr. Khim Dhoj Karki (MSC), and Mr. Sandesh (MSC). Furthermore, I am incredibly indebted to Dr. Paritosh Mudgal (MOIC) for guiding me in writing this research paper.

\section{Conflict of Interest}

No conflict of interest.

\section{Bibliography}

1. Pindborg Jens J and Satyavati M Sirsat. "Oral submucous fibrosis". Oral Surgery, Oral Medicine, Oral Pathology and Oral Radiology 22.6 (1966): 764-779.
2. Sachdev Prageet K., et al. "Zinc, copper, and iron in oral submucous fibrosis: A meta-analysis". International Journal of Dentistry 2018 (2018).

3. Dey Dipten., et al. "Evaluation of salivary copper and zinc levels in oral submucous fibrosis patients". International Journal of Health and Allied Sciences 2.2 (2016): 35-37.

4. Trivedy C., et al. "The upregulation of lysyl oxidase in oral submucous fibrosis and squamous cell carcinoma”. Journal of Oral Pathology and Medicine 28.6 (1999): 246-251.

5. Wang Tong-Hong., et al. "Lysyl oxidase and the tumour microenvironment”. International Journal of Molecular Sciences 18.1 (2017): 62.

6. More CB., et al. "Classification system for oral submucous fibrosis". Journal of Indian Academy of Oral Medicine and Radiology 24.1 (2012): 24.

7. Messadi DV. "Diagnostic aids for detection of oral pre-cancerous conditions". International journal of Oral Science 5.2 (2013): 59-65.

8. Shah N. "Oral cancer in India: Aetiological factors and prevention". Journal of the Indian Dental Association 60.3 (1989): 3-6.

9. Yadav A., et al. "Estimation of serum zinc, copper, and iron in the patients of oral submucous fibrosis". National Journal of Maxillofacial Surgery 6.2 (2015): 190.

10. Maher R., et al. "Role of areca nut in the causation of oral submucous fibrosis: A case-control study in Pakistan". Journal of Oral Pathology and Medicine 23 (1994): 65-69.

11. Hazarey VK., et al. "Oral submucous fibrosis: Study of 1000 cases from central India”. Journal of Oral Pathology and Medicine 36 (2007): 12-17.

12. Kumar LB., et al. "Evaluation of mast cells and burning sensation in various stages of Oral Submucous Fibrosis". Journal of Oral Biology and Craniofacial Research 10.4 (2020): 430-434.

13. Srivastava R., et al. "Prevalence of oral submucous fibrosis in patients visiting dental OPD of a dental college in Kanpur: A demographic study". Journal of Family Medicine and Primary Care 8.8 (2019): 2612. 
14. Zaidi JH., et al. "Radiochemical neutron activation analysis for trace elements of basic ingredients of pan". Journal of Radioanalytical and Nuclear Chemistry 253.3 (2002): 459-64.

15. Desai VD., et al. "Molecular analysis of trace elements in oral submucous fibrosis and future perspectives". Universal Research Journal of Dentistry 4.1 (2014): 26-35.

16. Shetty SR., et al. "Role of serum trace elements in oral precancer and oral cancer-a biochemical study". Cancer Research and Treatment 1.1 (2013): 1-3.

17. Balpande AR and Sathawane RS. "Estimation and comparative evaluation of serum iron, copper, Zinc and copper/zinc ratio in oral leukoplakia, submucous fibrosis and squamous cell carcinoma”. Journal of Indian Academy of Oral Medicine and Radiology 22.2 (2010): 73.

18. Tadakamadla J., et al. "Evaluation of serum copper and iron levels among oral submucous fibrosis patients". Medicina Oral, Patología Oral y Cirugía Bucal 16.7 (2011): e870-873.

19. Varghese I., et al. "Serum copper and zinc levels in pre-malignant and malignant lesions of the oral cavity". Oncology 44.4 (1987): 224-227.

20. Anuradha CD and Devi CS. "Studies on the hematological profile and trace elements in oral submucous fibrosis". Journal of Clinical Biochemistry and Nutrition 19.1 (1995): 9-17.

21. Kode MA and Karjodkar FR. "Estimation of the serum and the salivary trace elements in OSMF patients". Journal of Clinical and Diagnostic Research: JCDR 7.6 (2013): 1215.

22. Pillai KG and Burde KN. "Increased copper level in oral mucosal tissue of patients with submucous fibrosis and who chew areca nut products". West Indian Medical Journal 54.4 (2005): 270-271.

23. Yang YH., et al. "Epidemiological survey of oral submucous fibrosis and leukoplakia in aborigines of Taiwan". Journal of Oral Pathology and Medicine 30.4 (2001): 213-219.

24. Hosthor SS., et al. "Quantitative analysis of serum levels of trace elements in patients with oral submucous fibrosis and oral squamous cell carcinoma: A randomized cross-sectional study". Journal of Oral and Maxillofacial Pathology: JOMFP 18.1 (2014): 46.
25. Nasulewicz A., et al. "Role of copper in tumour angiogenesisclinical implications". Journal of Trace Elements in Medicine and Biology 18.1 (2004): 1-8.

26. Jayadeep A., et al. "Serum levels of copper, Zinc, iron and ceruplasmin in oral leukoplakia and squamous cell carcinoma". Journal of Experimental and Clinical Cancer Research: CR 16.3 (1997): 295-300.

\section{Assets from publication with us}

- Prompt Acknowledgement after receiving the article

- Thorough Double blinded peer review

- Rapid Publication

- Issue of Publication Certificate

- High visibility of your Published work

Website: www.actascientific.com/

Submit Article: www.actascientific.com/submission.php

Email us: editor@actascientific.com

Contact us: +919182824667 